\title{
Rice Biofortification-Progress and Challenges in Improving the Nutritional Value of Rice ${ }^{+}$
}

\author{
Russell Reinke 1,*, Mallikarjuna Swamy ${ }^{1}$, Abdul Kader ${ }^{2}$, Reynante Ordonio ${ }^{3}$, Untung Susanto ${ }^{4}$ \\ and Emily Arocena ${ }^{3}$ \\ 1 International Rice Research Institute (IRRI), Metro Manila 7777, Philippines; m.swamy@irri.org \\ 2 Plant Breeding Division, Bangladesh Rice Research Institute (BRRI), Gazipur 1701, Bangladesh; \\ abdulkaderbrri@yahoo.com \\ 3 Philippines Rice Research Institute (PhilRice), Maligaya, Science City of Muñoz 3119, Philippines; \\ rlordonio@philrice.gov.ph (R.O.); ec.arocena@philrice.gov.ph (E.A.) \\ 4 Indonesian Center for Rice Research (ICRR), Sukamandi 41256, Indonesia; untungsus2011@gmail.com \\ * Correspondence: r.reinke@irri.org \\ + Presented at the third International Tropical Agriculture Conference (TROPAG 2019), Brisbane, Australia, \\ 11-13 November 2019.
}

Published: 19 January 2020

\begin{abstract}
Rice is the principal source of calories for more than half of the world's population, and while an excellent source of energy is a relatively poor source of micronutrients. Developing rice varieties with increased levels of bioavailable micronutrients is a sustainable and complementary approach to tackle micronutrient malnutrition, and may be achieved through transgenic or conventional breeding approaches. Using the former approach Golden Rice has been genetically engineered to produce $\beta$-carotene in the grain to address the persistent and pervasive problem of vitamin A deficiency, while high levels of iron and zinc have also been achieved via a transgenic approach. The primary focus of conventional breeding is increasing zinc content. This paper reports on the progress and challenges in developing and delivering rice with improved micronutrient content.
\end{abstract}

Keywords: biofortification; micronutrient malnutrition; hidden hunger; transgenic approach; rice

(C) 2020 by the authors. Licensee MDPI, Basel, Switzerland. This article is an open access article distributed under the terms and conditions of the Creative Commons Attribution (CC BY) license (http://creativecommons.org/licenses/by/4.0/). 